\title{
Post-Traumatic Pyothorax: Epidemiology, Management and Prognosis in the Thoracic Surgery Department of the Donka National Hospital
}

\author{
Camara Alpha Kabinet, ${ }^{1,2}$, Camara Soriba Naby²,3, Balde Oumar Taibata ${ }^{2,4}$, \\ Diallo Amadou Sarah 2,3, Camara Mama Aissata',3, Magassouba Aboubacar Sidiki1,2, \\ Balde Abdoulaye Korse ${ }^{2,4}$, Toure Aboubacar ${ }^{2,5}$, Diallo Aissatou Taran ${ }^{2,5}$, \\ Diallo Biro ${ }^{2,4}$
}

${ }^{1}$ Department of Thoracic Surgery, Donka National Hospital, Conakry, Guinea ${ }^{2}$ Faculty of Sciences and Technic of Health Gamal Abdel Nasser University of Conakry, Conakry, Guinea

${ }^{3}$ Department of Visceral Surgery, Friendship Hospital Sino Guinean, Conakry, Guinea

${ }^{4}$ Department of Visceral Surgery, Donka National Hospital, Conakry, Guinea

${ }^{5}$ Department of General Surgery, Ignace Denn National Hospital, Conakry, Guinea

Email: cnabysoriba@yahoo.com

How to cite this paper: Kabinet, C.A., Naby, C.S., Taibata, B.O., Sarah, D.A., Aissata, C.M., Sidiki, M.A., Korse, B.A., Aboubacar, T., Taran, D.A. and Biro, D. (2021) Post-Traumatic Pyothorax: Epidemiology, Management and Prognosis in the Thoracic Surgery Department of the Donka National Hospital. Open Journal of Thoracic Surgery, 11, 83-88.

https://doi.org/10.4236/ojts.2021.114011

Received: June 10, 2021

Accepted: October 6, 2021

Published: October 9, 2021

Copyright (c) 2021 by author(s) and Scientific Research Publishing Inc. This work is licensed under the Creative Commons Attribution International License (CC BY 4.0).

http://creativecommons.org/licenses/by/4.0/ (c) (i) Open Access

\begin{abstract}
Pyothoraxes, also called thoracic empyemas, are defined by the presence between the two layers of the pleura, of a frankly purulent liquid, or of a shady or clear liquid but containing a majority of altered polynuclear cells with germs direct examination. They are said to be traumatic when they follow a thoracic trauma whatever the mechanism; usually a pre-existing post-traumatic pleural effusion. The general objective of this study was to help identify the epidemiological and prognostic factors in the management of post-traumatic pyothorax in the Thoracic Surgery Department of the Donka National Hospital. Methodology: This was a descriptive retrospective study covering a period of 2.5 years from 01/06/2016 to 31/12/2018 carried out in the Thoracic Surgery Department of the Donka National Hospital. Results: During the study period, 17 cases of post-traumatic pyothorax were observed among the 288 files of admitted and hospitalized patients. In the course of this study, a rate was $5.90 \%$. The most affected age group was 1 to 5 years old. The male sex was in the majority (76.5\%). The most common occurrence was the fall, i.e. $41.2 \% .47 \%$ of patients consult after 60 days. Chest pain and dyspnea were the main symptoms during our study (82.3\%). Antibiotics and analgesics dominated the medical treatment used in $100 \%$ of the cases and pleural drai-
\end{abstract}


nage was the first line surgical treatment practiced in $88.2 \%$ of the cases. The prognosis is favorable without sequelae in $52.9 \%$ of cases with an average hospital stay of 9 days. Post-traumatic pyothorax is a serious pathology involving the vital and functional respiratory prognosis, hence the need to diagnose and treat it early.

\section{Keywords}

Pyothorax, Trauma, Epidemiology, Management, Prognosis, Surgery, Donka

\section{Introduction}

Pyothoraxes, also called thoracic empyemas, are defined by the presence between the two layers of the pleura, of a frankly purulent liquid, or of a shady or clear liquid but containing a majority of altered polynuclear cells with germs under examination [1]. They are said to be traumatic when they follow a trauma to the chest whatever the mechanism, generally a pre-existing post-traumatic pleural effusion.

Although the diagnosis of empyema is suspected on physical examination and a chest X-ray [2] [3] [4] [5] [6], confirmation requires an exploratory puncture, which brings a purulent fluid.

The thoracic empyema, is considered to be the inflammatory process in a preformed anatomical space between the two sheets, the visceral and parietal pleura, was one of the first recognized thoracic pathological entities that had been a therapeutic challenge today. Since then, it has so far seemed to resist evidence-based approaches. Paradoxical result of the increase in life expectancy, the improvement in the survival of malignant diseases and the criteria of operability extended inside and outside the field of thoracic surgery, the pool of candidates potential for thoracic empyema widened. The abuse of antibiotics has led to an increase in the number of cases resistant to treatment, and tuberculosis has not ceased to be a permanent threat either. Immunocompromised conditions, either iatrogenic (transplantation and cancer therapy) or resulting from drug abuse and HIV [1], impose an additional risk of developing empyema in the chest. The absolute need for commonly accepted definitions and a consensus in the categories is highlighted by the fact that the empyema of the thorax is located at the interface between two major surgeries namely thoracic surgery and pneumonology on the one hand, trauma surgery on the other hand.

In the acute stage, active medical treatment leads to restitution of the pleural lesions. However, the transition to chronicity is frequent, and at this stage only surgical treatment can definitively settle the infection [1]-[9].

We report our experience through the study of the records of 17 patients with empyema post-traumatic neck in Warders surgical facilities chest Donka National Hospital. The objective of this study was to help identify the epidemiolog- 
ical factors and the prognosis in the management of post-traumatic pyothorax in the Thoracic Surgery Department of the Donka National Hospital.

\section{Material and Methods}

This was a retrospective study of descriptive type of a lasting two and a half years from June 2016 to December 2018 conducted an in department of Thoracic Surgery of the National Donka Hospital. Included were all usable records of patients who were hospitalized for post-traumatic pyothorax. Were not included all the unusable files and dossiers are patients received $s$ and treated for other conditions. The variables studied were age, sex, socio-professional background, etiologies, evolution, clinical and para-clinical aspects, management and prognosis of post-traumatic pyothorax (medical treatment, surgical gesture). The quantitative variables were expressed as mean \pm standard deviation or in median (extremes) and the qualitative variables in absolute number or in percentage (\%).

\section{Results}

During the study period, 17 cases of post-traumatic pyothorax were observed among the 288 files of admitted and hospitalized patients. The frequency was $5.90 \%$. The average age was 8.64 years with a maximum between 1 and 5 years and the extremes ranging from 1 to 26 years. The male sex was dominant with 13 cases (76.5\%) against 4 female cases (23.5\%) with a sex ratio of 3.25. Out-of-school children were the most affected with 8 cases (47\%) followed by pupils/students with 7 cases (41.2\%) (Table 1).

The average time to trauma before the first consultation was 60 days. The clinical signs were dominated by chest pain and dyspnea in 14 cases each (82.3\%), pleural effusion fluid syndrome in 12 cases (70.6\%), appear in Table 2.

The chest X-ray revealed 11 cases of free post-traumatic pleural effusion (64.7\%), followed by 5 cases of post-traumatic mixed pleural effusion $(29.4 \%)$ and 1 case of pleural effusion encysted post-traumatic fluid (5.9\%). The germ most frequently isolated was Staphylococcus aureus in 12 cases (70.6\%) and the germ involved was undetermined in 3 cases (17.6\%) (Table 3 ).

Table 1. Distribution of patient records according to the circumstances of occurrence.

\begin{tabular}{ccc}
\hline Circumstance of occurrence & Effective & Percentage \\
Fall & 7 & 41.2 \\
AVP & 4 & 23.5 \\
Sports accident & 3 & 17.6 \\
Domestic accident & 1 & 5.9 \\
Ingestion/inhalation of foreign bodies & 2 & 11.8 \\
Total & 17 & 100 \\
\hline
\end{tabular}


Table 2. Frequency of patient records according to clinical signs.

\begin{tabular}{ccc}
\hline Clinical signs & Effective & Percentage \\
\hline Chest pain & 14 & 82.3 \\
Dyspnea & 14 & 82.3 \\
Fluid pleural effusion syndrome & 12 & 70.6 \\
Cough & 9 & 53 \\
Fever & 9 & 53 \\
Unsatisfactory general condition & 9 & 53 \\
Respiratory distress syndrome & 7 & 41.2 \\
General condition deterioration & 6 & 35.3 \\
Mixed pleural effusion syndrome & 5 & 29.4 \\
General condition satisfactory & 2 & 11.8 \\
Weight loss & 1 & 5.9 \\
Asymmetry of the thorax & 1 & 5.9 \\
\hline
\end{tabular}

Table 3. Frequency of patient records according to therapeutic management.

\begin{tabular}{ccc}
\hline Supported & Effective & Percentage \\
\hline ATB & 17 & 100 \\
Analgesic & 17 & 100 \\
Isotonic solution & 16 & 94.1 \\
NSAIDs & 14 & 82.3 \\
Gastric anti-secretory & 14 & 82.3 \\
Oxygen therapy & 3 & 17.6 \\
Respiratory physiotherapy & 3 & 17.6 \\
Pleural puncture & 3 & 17.6 \\
Pleural drainage & 15 & 88.2 \\
\hline
\end{tabular}

The prognosis was favorable in 9 cases (53\%) and unfavorable in 7 cases (41.2\%) with a type of complication such as parietal suppuration, recurrence and pachypleuritis. The average length of hospital stay was 9 days with extremes ranging from 6 to 54 days.

\section{Discussion}

During our study over a period of 2 and a half years post-traumatic pyothorax represented $5.90 \%$ with 17 cases out of a total of 288 patient files. Ondo N'dong F. et al. in Gabon in 2007 [5] reported a prevalence of 4\%. This increase could be explained by the late admission of certain patients to the only specialized service. The patients in our series have a younger age with a maximum frequency between 1 and 5 years and an average of 8.64 years. The predominance of men is found in many studies. It reaches $80 \%$ in the study by Sidayne M. and has 1 [1] and $76.47 \%$ for Khaoula C. [4]. Similarly in our series, $76.5 \%$ of our patients were male. It is likely linked to the greater exposure of men to causative abnor- 
malities such as trauma to the chest and physical activity. Out-of-school children were the most affected. This result could be explained by the fact that post-traumatic pyothorax readily occurs in disadvantaged subjects with deplorable hygienic and food conditions with a low socio-economic level.

In our study, falling was the most frequent occurrence followed by road accidents (Table 1). This could be explained on the one hand by the increase in the incidence of post-traumatic pyothorax in children who fall repeatedly due to their bone hinge which is still fragile and on the other hand by the non- compliance with traffic laws. On the clinical plan, $47 \%$ of our patients had consulted in thoracic surgery 60 days after the trauma (Table 2). This situation could be justified by the ignorance of health workers in the outskirts of the pathology, responsible for the delay in diagnosis and treatment. The general condition was generally unsatisfactory. The reasons for consultation were dominated by chest pain and dyspnea which corresponds perfectly to the subjective symptomatology of pleuro-pulmonary suppurations described in the literature by several authors as observed by Dr. Issa O. B. [3] and Ondo N'dong F. [5]. Fluid pleural effusion syndrome was classic in $70.6 \%$ on physical examination and physical examination associated with the analysis of radiographic images revealed $64.7 \%$ of post-traumatic pyothorax followed by $29,4 \%$ pyopneumothorax and $5.9 \%$ post traumatic pyothorax encysted. This result agrees with the data of Drissa O.B. [3] and Ouédraogo Z. A. et al. [7]. This would depend on the anatomopathological stage of the pyothorax at which the patients consult in thoracic surgery. Staphylococcus aureus was the main causative agent. Yariba D. [2] and Fofana D. [8] found the same predominance in Bamako. It is probably linked to the resistance of staph strains to common antibiotics.

Regarding the treatment, the majority of our patients were treated by thoracic drainage associated with an antibiotic therapy adapted to the antibiogram (the association of several antibiotics, in particular a dual therapy or a triple therapy was generally the rule) (Table 3 ). As for respiratory physiotherapy, it was almost not systematic because of our study population which was mainly children under 5 years old who could not perform respiratory physiotherapy. These data are comparable to the studies by Khaoula C. in Morocco in 2018 [4]. This would explain the importance of the association of respiratory physiotherapy with pleural drainage in order to potentiate the efficiency of pleural drainage and rapid pulmonary functional restoration in order to avoid the occurrence of complications. As for the non-practice of the decortication thoracotomy sometimes recommended in the event of failure of the pleural drainage, it could be justified on the one hand by the insufficiency of our technical platform and on the other hand by the limited socio-economic level of our patients.

The prognosis was favorable in 53\% with complete healing and unfavorable in $41.2 \%$ with a type of complication such as parietal suppurations, recurrences and pachypleuritis with a mortality rate of $0 \%$. Is this a coincidence or the small size of our sample? Sidayne M. and al [1] reported a favorable evolution in $82 \%$ and a mortality rate at $8 \%$. This would explain the gravity of the pathology and its 
repercussions on the vital and functional respiratory prognosis by the after-effects it causes, despite the treatment.

\section{Conclusions}

Post-traumatic pyothorax is a serious condition and is a major problem in the Republic of Guinea. It emerges from our study that it is a pathology which brings into play the vital prognosis, and the respiratory respiratory prognosis by the after-effects it causes, whatever the treatment. Its treatment uses thoracic drainage, but pleuro-pulmonary decortication, sometimes associated with parenchymal excision, is often necessary in view of the size of the pleural shell and lesions of parenchymal destruction. Morbidity is heavy, hence the need to diagnose and treat post-traumatic pyothorax early before the stage of encystment and the transition to chronicity.

In addition, aseptic measures should be strengthened and antibiotic prophylaxis improved in pulmonary excision surgery.

\section{Conflicts of Interest}

The authors declare no conflicts of interest regarding the publication of this paper.

\section{References}

[1] Sidayne, M. and Boughalem, M. (2012) Le pyothorax (Retrospective Study of 25 Cases). Thesis of Medicine, Marrakech, 3.

[2] Yariba, D. (2006) Clinical and Progressive Profile of Purulent Pleurisy in a Specialized Hospital Environment in Bamako. Doctoral Thesis, Bamako, 111.

[3] Drissa, O.B. (2008) Surgical Aspects of Pyothorax in Surgery Department A of CHU Point G. Doctoral Thesis, Bamako, 103.

[4] Khaoula, C. (2018) Surgical Management of Pyothorax (about 153 Cases). Thesis of Medicine, Fez, 131.

[5] Ondo N'dong, F., Diallo, O.K.F., Mbamendame, S., Nkole, A.M., Kaba, M.M. and Ndong, M.A. (2007) Pyothorax: Clinical and Therapeutic Aspect in Libreville about 24 Cases. Ann Afr Chir Thor Cardiovasc., 2, 124-128.

[6] Guyon, G., Allal, H., Lande, M. and Rodiere, M. (2005) Child's Pleurisy: Montpelliéraine Experience. Archives of Pediatrics, 12, S54-S57.

https://doi.org/10.1016/S0929-693X(05)80013-2

[7] Ouedraogo, Z.A., Ouedraogo, M., Badoum, G.S.M., Zigani, A., Meda, C.Z. and Sawadogo, A. (2003) Problem of Purulent Pleurisy at the National Hospital Center of Sourosanon in Bobo-Dioulasso Concerning 129 Hospitalized Cases. Med., Black Africa, 50, 509-512.

[8] Fofana, D. (2006) Cytobacteriological Aspect of Pleural Fluids Encountered in the Pneumo-Phthisiology Department of the G-Spot Teaching Hospital and Study of the Sensitivity to Antibiotics of Isolated Germs. Thèse Pharmacie, Bamako, 78 p.

[9] Letheulle, J., Kerjouan, M., Bénézit, F., De Latour, B., Tattevin, P., Piau, C., et al. (2015) Parapneumonic Pleural Effusions: Epidemiology, Diagnosis, Classification, Treatment. Respiratory Disease Review, 32, 344-357. https://doi.org/10.1016/j.rmr.2014.12.001 